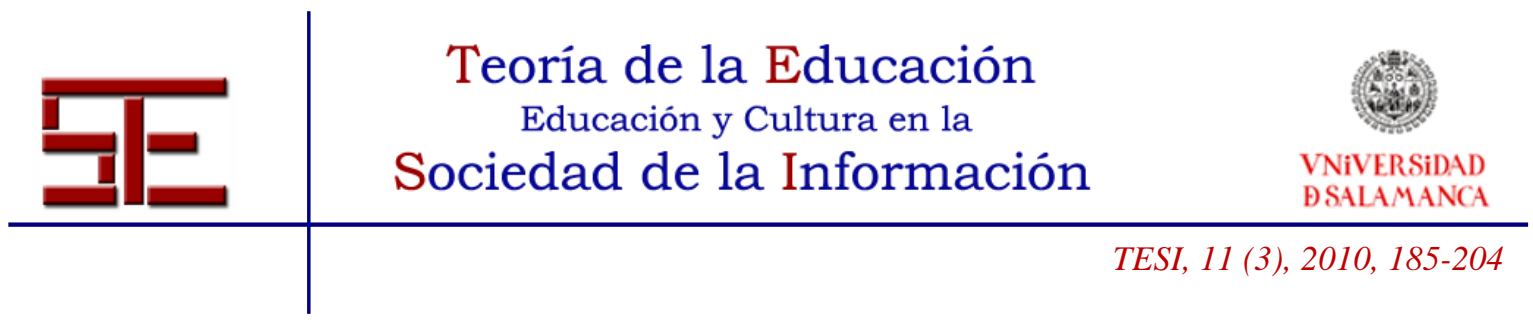

\title{
JUEGO DE ROL Y EDUCACIÓN, HACIA UNA TAXONOMÍA GENERAL
}

Resumen: La definición del juego de rol suele resultar ambigua y deja atrás alguna de las modalidades del mismo. Se propone por tanto una integración de los conceptos narración, representación y juego para hallar un término aceptable. Posteriormente se trabaja con un acercamiento taxonómico inicial en función de los siguientes criterios: modalidad básica, tipos o partes de manuales, mundos posibles en relación al mundo real y géneros. Para cada clase se hace un panorama de capacitaciones y aplicaciones pedagógicas. Todo queda como un marco genérico descriptivo a partir del cual puede empezar un acercamiento metodológico multidisciplinar con especialistas tanto de elaboración de contenidos como asesores pedagógicos.

Palabras clave: juegos de rol; educación; pedagogía y juegos de rol

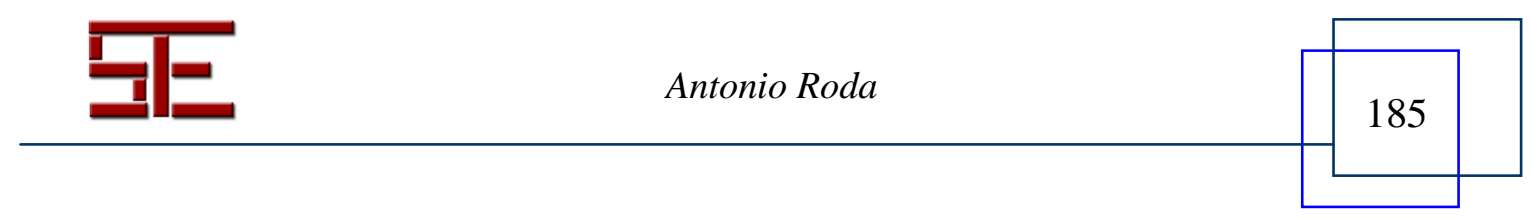




\title{
ROLEPLAYING GAME AND LEARNING, TOWARD A GENERAL TAXONOMY
}

\begin{abstract}
The definition of Role-Playing Game tends to be ambiguous and always excludes some of its modalities. To achieve an acceptable term, we propose the integration of the concepts of narration, representation and game. Subsequently, we should work with an initial taxonomic approach with the next criteria: basic modality, types and parts of manuals, possible worlds in connection with the real world, and genre. Each type has a different variety of qualifications and pedagogic applications. Everything sets up a descriptive generic framework from where we can start a multidisciplinary methodological approach with specialists in the content creation and pedagogic advisors.
\end{abstract}

Key words: role play; education; teaching and role play

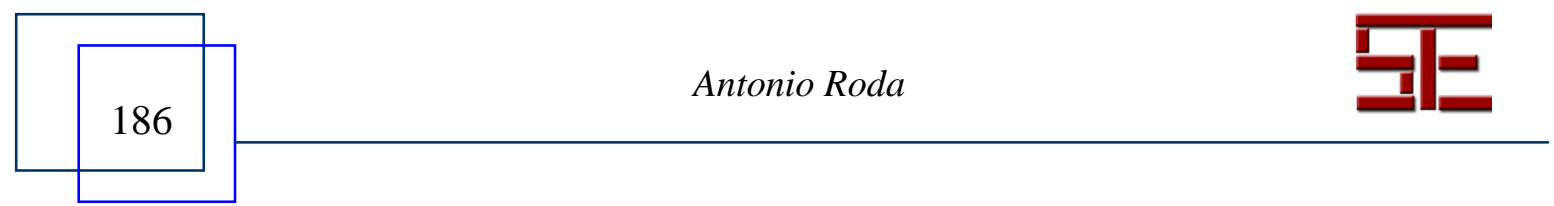




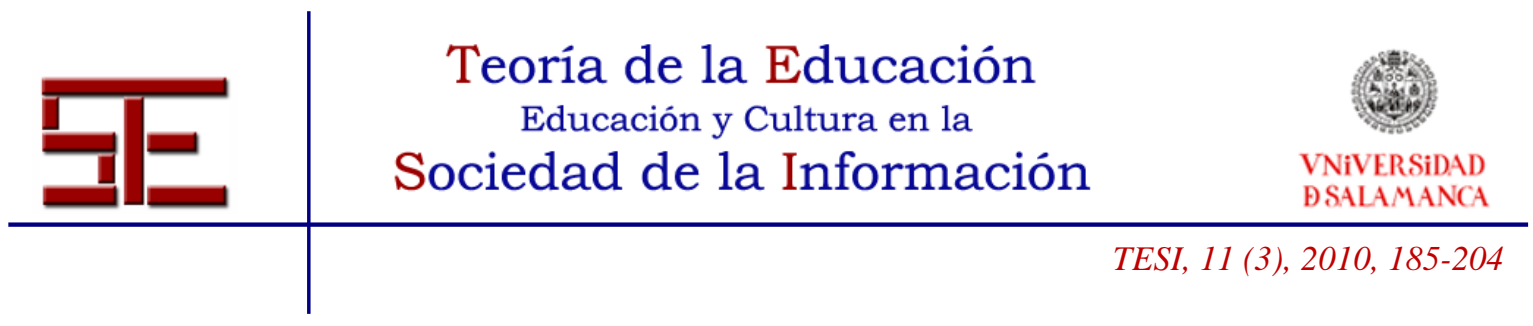

\title{
JUEGO DE ROL Y EDUCACIÓN, HACIA UNA TAXONOMÍA GENERAL
}

Fecha de recepción: 16/07/2010; fecha de aceptación: 23/10/2010; fecha de publicación: 30/11/2010

\author{
Antonio Roda \\ ant.roda@gmail.com \\ Universidad de Sevilla
}

\section{1.- INTRODUCCIÓN.}

Juego de rol, dinámica de roles, juegos de roles son términos que se están utilizando indistintamente en el ámbito educativo, sobre todo en los cursos de Formación Profesional Ocupacional y Formación Continua, a partir de hoy FPE, Formación Para el Empleo. Esto se debe a que las expresiones anglófonas Role play y Role-Playing Game se confunden, aunque estén obviamente relacionadas:

\footnotetext{
role playing (also role play) noun [mass noun] 1 chiefly Psychology the acting out or performance of a particular role, either consciously (as a technique in psychotherapy or training) or unconsciously, in accordance with the perceived expectations of society as regards a person's behaviour in a particular context.

2 participation in a role-playing game.

- DERIVATIVES role-play verb. role player noun.

role-playing game noun a game in which players take on the roles of imaginary characters who engage in adventures, typically in a particular fantasy setting overseen by a referee, (Soanes y Stevenson, 2006, 1527) ${ }^{1}$
}

El acto de la participación es, por tanto, lo que más confusiones ha ido generando en todo momento. Pero si se leen manuales de rol de distinto tipo puede observarse que tampoco se genera ahí una definición clara y concisa de en qué consiste un juego de rol. Tienden a buscar una clara ambigüedad que los relacione con la narración, la interpretación, el simulacro o el estímulo de la imaginación. Tomando en este punto inicial como ejemplo un manual español:

(...) (diálogo, imaginación e interpretación) son la base del juego de rol. (...)

En el juego de rol un Director de Juego imagina una situación, una aventura, elaborando un guión. Un grupo de jugadores le escuchan mientras narra el

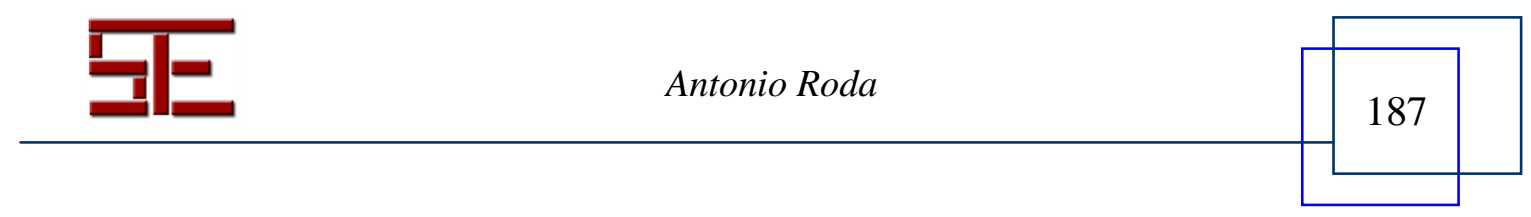




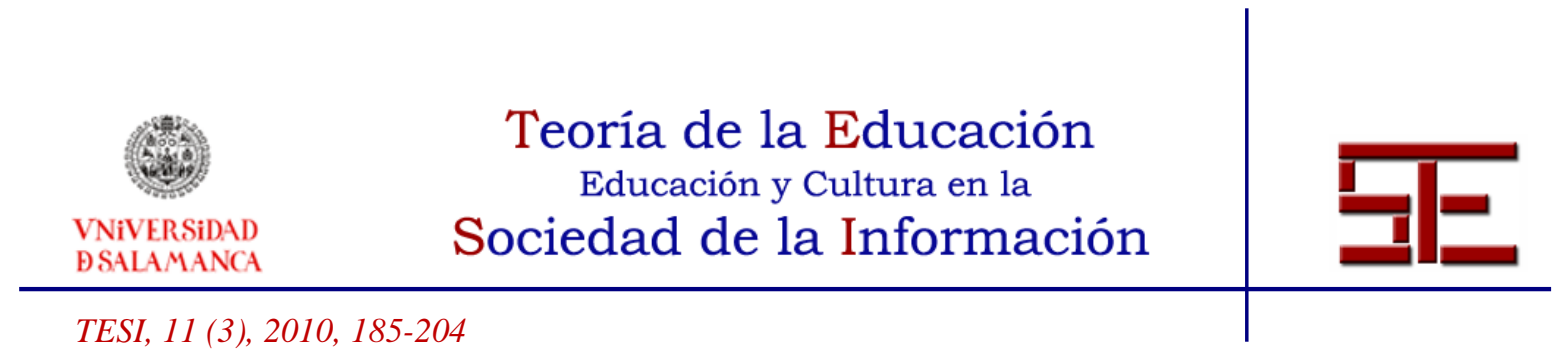

planteamiento inicial. Dichos jugadores, sin embargo, toman parte activa en la
narración: cada uno de ellos interpreta el rol, el papel de uno de los
protagonistas de esta historia. Una narración que es de algún modo como la
vida: el Director de Juego expone la situación, los jugadores la imaginan y
reflexionan sobre el mejor modo de resolverla. (...) La decisión final depende
siempre del jugador (Ibáñez, 2001, 11).

Esta definición muestra los elementos antes mencionados. Se insiste sobre todo en la narración, aunque se deja un espacio para el diálogo y el tomar el papel como inicio de la interpretación, se insiste en la imaginación, y por último el planteamiento de resolución de situaciones se acerca a la postura aplicativa del simulacro.

Por otro lado, al tratar con el aficionado de los juegos de rol se establece un conflicto dependiendo de qué modalidad de juego de rol practique. Por ejemplo, el jugador de mesa tiene tendencia a una perspectiva de su práctica como más estimuladora de la imaginación, el del rol en vivo (dependiendo de su tipo también) más activo o que profundiza más en el personaje, y el del videojuego más acorde con las nuevas tecnologías. Es común hablar por los dos primeros grupos que el tercero no es rol de verdad, y en los países nórdicos existe la tendencia a desvincularse del juego de rol en mesa defendiendo el rol en vivo como arte de representación (Fatland, 2005, 12), haciendo hincapié en que el acrónimo acordado para la modalidad en vivo, $L A R P^{2}$, no incluye la palabra Game. Si consultamos estudios previos, podemos comprobar que esta exclusión y este tratamiento despreciativo se han ido produciendo en la subcultura del ocio desde finales de los setenta (Fine, 1983,37) cuando el juego de rol estaba en escisión de los juegos de estrategia.

Al igual que pretenden los manuales, pero desde una perspectiva más académica, con este artículo se pretende defender la definición ya elaborada en el trabajo de investigación del Diploma de Estudios Avanzados del investigador, para a partir de ella hacer un estudio taxonómico. Éste servirá de panorama inicial de los principios pedagógicos, para que pueda profundizarse en posteriores trabajos mediante una metodología clara.

\section{2.- DEFINICIÓN DEL JUEGO DE ROL}

Además del ya citado texto de Ricard Ibáñez, tomemos como ejemplos representativos las siguientes definiciones de juego de rol. Éstos se mostrarán mediante un criterio

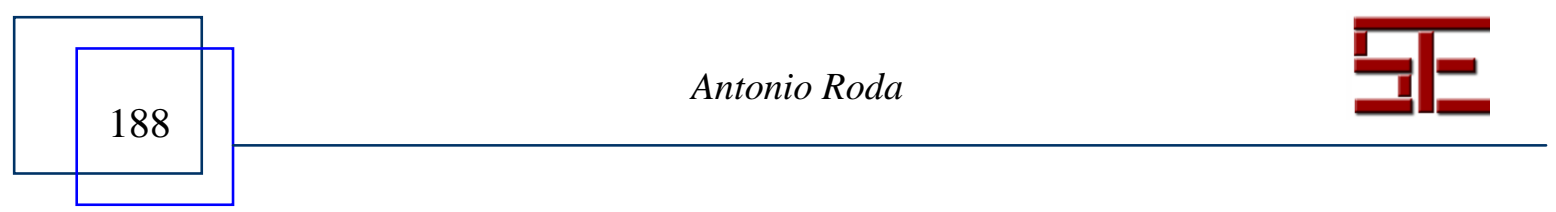




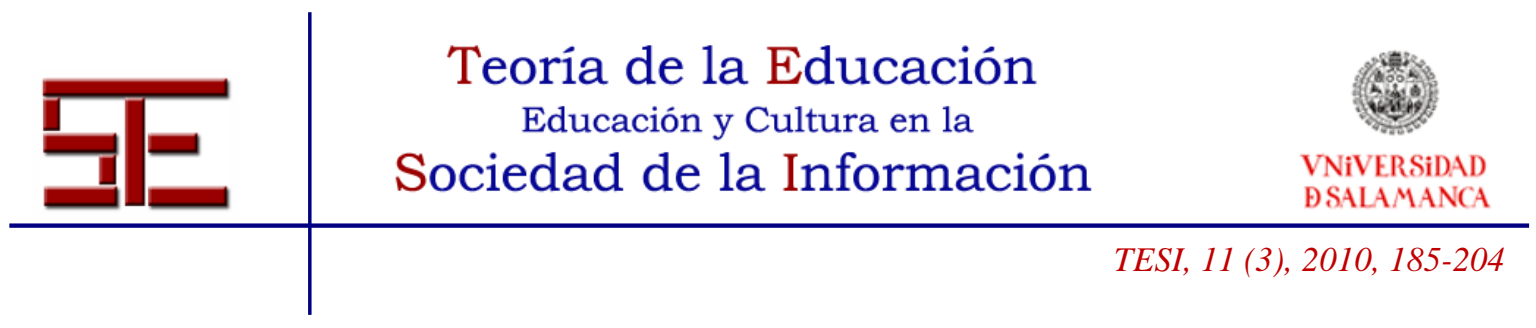

cronológico que permitirá contemplar la evolución que se ha producido en esta forma de ocio.

Tomemos como inicio la recopilación de manuales de Dungeons \& Dragons realizada por Frank Mentzer en 1983. En ella, se comenzaba explicando el concepto de "dungeon" como "[...] a group of rooms and corridors in which monsters and treasures can be found"3 (Mentzer, 1983, 2). Por tanto, el inicio de este juego lo que vende es aventura y confrontación violenta contra monstruos. Posteriormente, encontramos otro epígrafe con la pregunta "What is role playing" (ibíd.), a lo que ante el concepto de actuación comienza definiendo otra de las facetas del juego de rol: "This is a roleplaying game. That means that you will be like an actor, imagining that you are someone else, and pretending to be that character. You won't need a stage, though, and you won't need costumes or scripts. You only need to imagine" ${ }^{4}$ (ibíd.).

Sigamos con La llamada de Cthulhu (Petersen, 1994), que es considerado el juego de rol favorito de varios investigadores universitarios (Ranera Sánchez, 1999; Hughes, 1988). En él, se trabaja el concepto de juego de rol de la siguiente manera:

\begin{abstract}
Los jugadores de La llamada de Cthulhu interpretan el papel de intrépidos investigadores de lo desconocido, que intentan exponer, comprender y quizás destruir los horrores, secretos y misterios de los Mitos de Cthulhu. Se precisa de un moderador de juego llamado 'Guardián de los Arcanos' (o Guardián a secas), cuyo papel es el de crear situaciones para que los personajes se enfrenten a ellas, dentro siempre de las reglas del juego. [...]

El deber de los jugadores es el interpretar un personaje dentro de los límites de lo que éstos conocen, y también ellos deben conservar el equilibrio del juego. $[\ldots]$

Jugar dentro de las limitaciones de sus personajes representa un reto a la imaginación de los jugadores, y es precisamente esta situación la que convierte a este juego en un JUEGO DE ROL. Los personajes interpretan cada uno el rol de su personaje, como si sólo este existiera, y esta es la parte más difícil y satisfactoria del juego (Petersen, 1994, 7).
\end{abstract}

Esta definición hace especial hincapié en los elementos de interpretación, creación de situaciones y resolución de las mismas. En verdad, es bastante parecida a la que se planteó en la introducción en el manual de Ricard Ibáñez. Esto se debe a que La llamada de Cthulhu fue el primer juego publicado por la editorial Joc Internacional, que fue a su vez la primera editorial especializada en juegos de rol en España. En 1991 publicó, Aquelarre, que también fue novedad como juego de rol español.

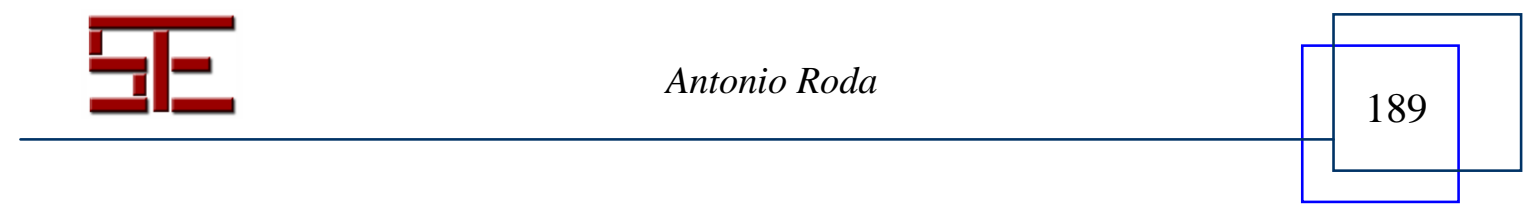




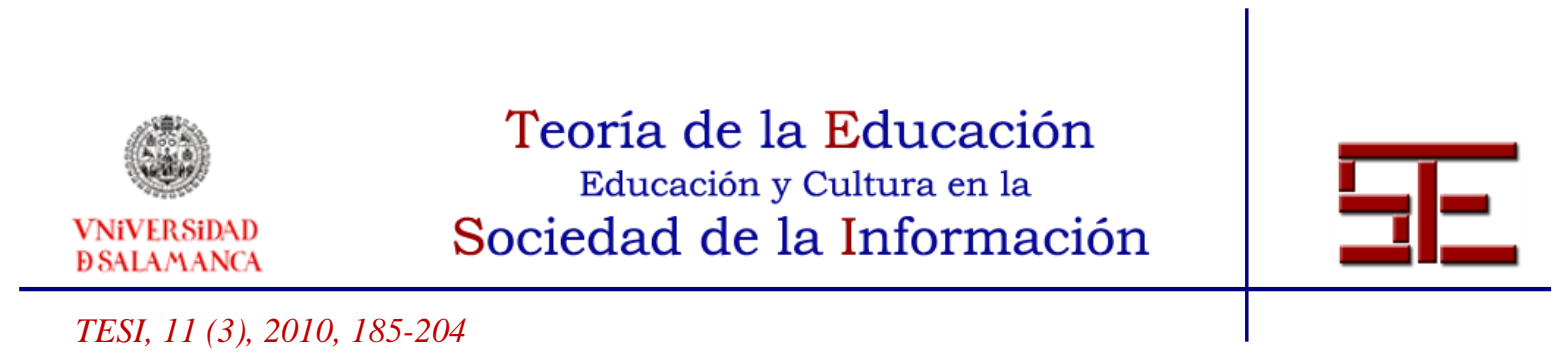

Como tercer ejemplo se llega a una serie de juegos que se autodenominan como narrativos. De hecho, en su origen pretendían una escisión del juego de rol:

El objetivo de un juego narrativo es participar verbalmente en la experiencia de cooperar en una historia. Todos hablan para contribuir a la historia que esté desarrollándose. [...]

El juego en Príncipe Valiente es verbal e imaginativo. La acción tiene lugar en las mentes de los jugadores. El juego es en su totalidad un intercambio verbal, que se interrumpe cuando se lanzan las monedas para resolver conflictos. Los jugadores cooperan para crear una experiencia fantástica que compartir, guiados por uno de ellos, que asume el papel de Narrador. [...] (Stafford, 1990:5)

Se puede contemplar la tendencia inicial a incentivar la actuación verbal frente al sistema de juego, así como el énfasis en los elementos narrativos sacrificando para ello las reglas mecánicas cuando fuera necesario. Esto se acrecentará en manuales posteriores, de los cuales merece la pena mencionar el antiguo Mundo de Tinieblas por su repercusión.

En cuarto y último lugar, se encuentran una serie de manuales de rol experimental dirigidos a jugadores veteranos. Aunque hasta este punto se ha podido deducir que dependiendo del libro los conceptos aplicables al juego de rol oscilan entre un punto y otro, esta nueva tendencia obvia sus definiciones:

\footnotetext{
¿Qué es un juego de rol?

Este libro está dirigido a jugadores de rol experimentados. Si no sabes lo que es jugar al rol, ¿cómo diablos has conseguido una copia de este libro?

$\mathrm{Si}$ crees que éste es un libro acerca de fenómenos sobrenaturales genuinos y reales, o que enseña a lanzar conjuros o a ser un verdero vampiro, estás seriamente confundido.

$\mathrm{Si}$ crees que los juegos de rol pueden ser una forma de entretenimiento interesante pero no pillas del todo el concepto básico, búscalo en Internet o haz que un amigo friki te lo explique. (Laws, 2006: 6)
}

Esta no definición sirve de referente contextual de elitismo imperante en esta forma de ocio, ya mencionado previamente por Ranera Sánchez (1999) y Fine (1983). Queda de fondo el concepto de que "se sabe" qué es el juego de rol, pero cada jugador y creador lo enfoca desde una perspectiva, generando una visión segmentada y excluyente.

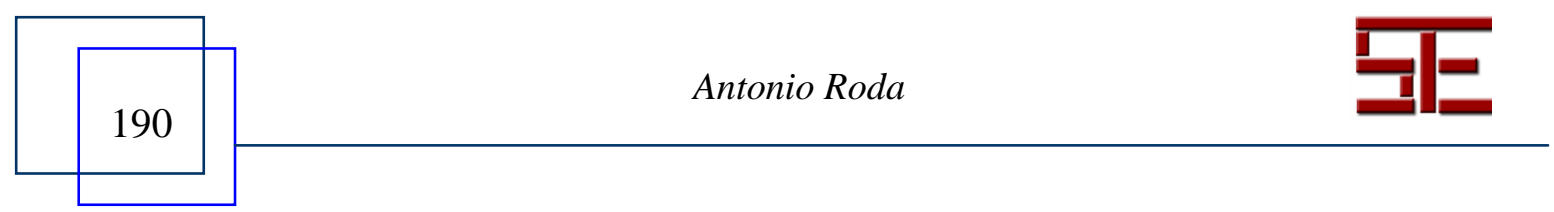




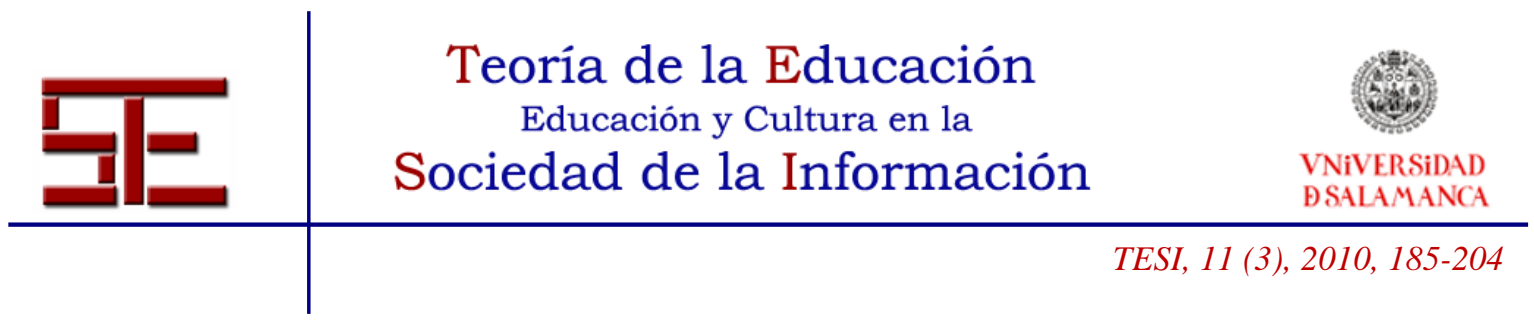

Pero hasta este momento lo que se ha contemplado no es más que una de las modalidades generales del juego de rol, en mesa. Todos los manuales hacen referencia a la narración y actuación verbales, con alguna mecánica de juego basada, sobre todo, en variables aleatorias. Pero con la llegada de la siguiente modalidad, en vivo, surgen cambios significativos.

El primer acercamiento en España fue a través de Killer. Éste comenzaba con un planteamiento radicalmente distinto a lo antes mencionado: "En Killer, no creas un personaje de papel... el personaje eres tú", (Jackson, 1991,3). Seguía a su vez con la aparente contradicción de términos "El objetivo en Killer es eliminar a los oponentes (...). Bajo la supervisión de un director de juego, los jugadores intentan anotarse "asesinatos" por medio de pistolas de ventosas, "granadas" de confetti, trampas cazabobos hechas con globos $\mathrm{y}$ decenas de otros ingeniosos artilugios. Los supervivientes ganan" (Ibid.).

El verdadero problema está en que Killer no se comercializó como juego de asesinato, sino como juego de rol. En verdad, sólo una de las maneras de juego de Killer recibía el nombre "de rol", "En una partida de rol, cada jugador adopta un nombre, pasado y personalidad distinta de la suya propia. Los jugadores pueden adoptar alias en cualquier partida, tanto mejor si aterrorizan o confunden a sus enemigos [...]. Cada jugador debería adoptar un tipo de personalidad, como las descritas a continuación. Cada tipo tiene sus ventajas y desventajas" (Jackson, 1991, 13). Por tanto, lo que se está haciendo es entrar dentro de los juegos de asesinato en el ámbito de los juegos de rol.

La siguiente inclusión en el mercado fue la del Teatro de la mente, que se autoconsidera un "juego interactivo" en el cual mezcla la tendencia de las "variantes del juego de mesa" con los "juegos de fantasía en vivo" para así centrarse en "contar una buena historia" (Rein•Hagen, Lemke y Tinney, 1999, 8-9). A nivel definitorio básico, se mueve en los conceptos de "En cierto modo, ni siquiera es un juego. No hay tablero, ni dados, ni reglas para conseguir la victoria" (Rein•Hagen; Lemke y Tinney, 1999, 7). Juega con la premisa básica de la continuidad narrativa "La historia debería ser lo primero. Si todos los participantes en una discusión pueden ponerse de acuerdo para resolverla, ignora las reglas" (Ibíd.).

En cuanto al videojuego, hay que recurrir a los estudios académicos en pos de una definición. Al principio recibieron esta terminología aquellos que usaban el sistema de algún juego de rol en mesa para cuantificar las operaciones matemáticas necesarias que

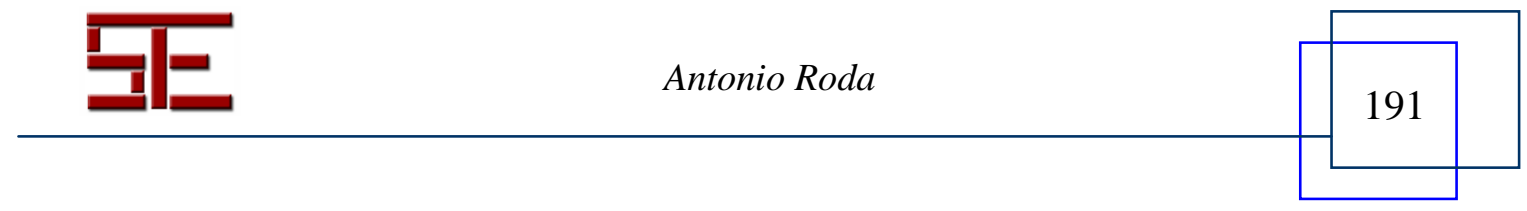




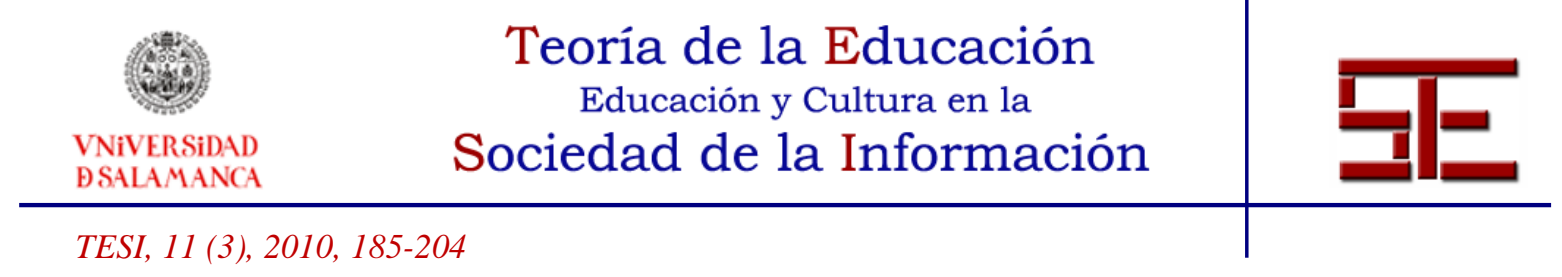

permitieran la emulación de las aventuras (Taylor; 2006: 21 y Castronova; 2005, 9). Se generaba un entorno virtual, ya fuera mediante texto o imágenes, en el cual se desarrollaba la acción. Además del interfaz gráfico, se experimentó con las opciones de multijugador, llegándose a los MMORPG (Multiplayer Massive Online Roleplaying Game) en los que miles de usuarios comparten entorno de juego.

Además, hay que considerar el rol por escrito. Éste comenzó como una progresión de los wargames por correo postal ya en los años setenta (Fine, 1983). Con el acceso a Internet se produce la revolución, permitiendo desde la práctica a través del correo electrónico hasta el foro, chat o servicios de mensajería. Se genera software específico como Fantasy Ground, para poder emular partidas en mesa de Dungeons \& Dragons, o sistemas de juego a través de páginas web.

A nivel definitorio el único problema que se nos plantea es que, salvo la modalidad de videojuego, en el resto hay interacción real con otros jugadores. Pero para aclarar este concepto debemos recurrir al concepto de virtual. Éste recibe entre otras la acepción de potencial (Ryan, 2004, 90), siendo los diversos subprogramas los que cumplen la función emuladora del entorno real.

Salvando ese escollo, y sobre todo tras integrar los conceptos de Daniel Mackay, se puede llegar a la siguiente definición de juego de rol, la cual resulta suficientemente integradora de las distintas modalidades así como diferenciadora de otras formas de ocio:

Un juego de rol es una actividad lúdica consistente en interpretar uno o varios personajes en un relato; como juego, es libre en su elección y está sometido a reglas, que serán particulares para cada juego de rol en concreto. Como interpretación, consiste en intentar no ser uno mismo, tomando decisiones e intentando actuar como el personaje del mundo de juego. Y como narración es un relato interactivo, en un entorno imaginario, donde se encontrará con otros personajes en diversos escenarios, moviéndose a través de las acciones que determine y los acontecimientos que le ocurran.

Téngase en cuenta que en ningún momento se habla de narración ni de interpretación en grado superlativo. Se trata de un proceso gradual, en el cual un participante puede decidir entrar en mayores o menores complejidades del proceso de dejar de ser uno mismo para pasar a ser un personaje de ficción. Así, "The role-playing game exhibits a

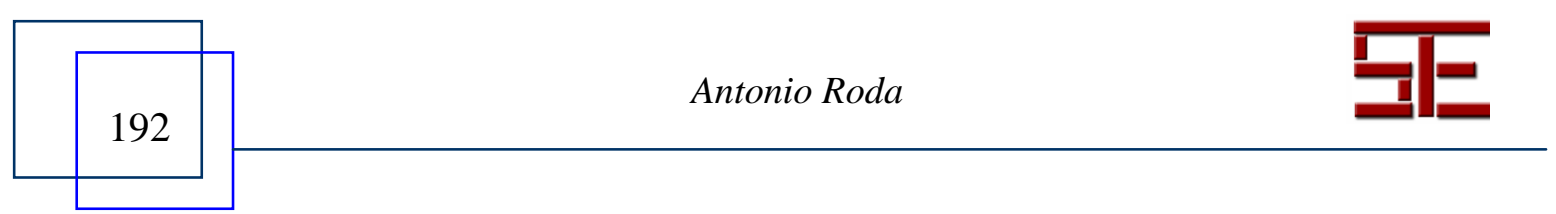




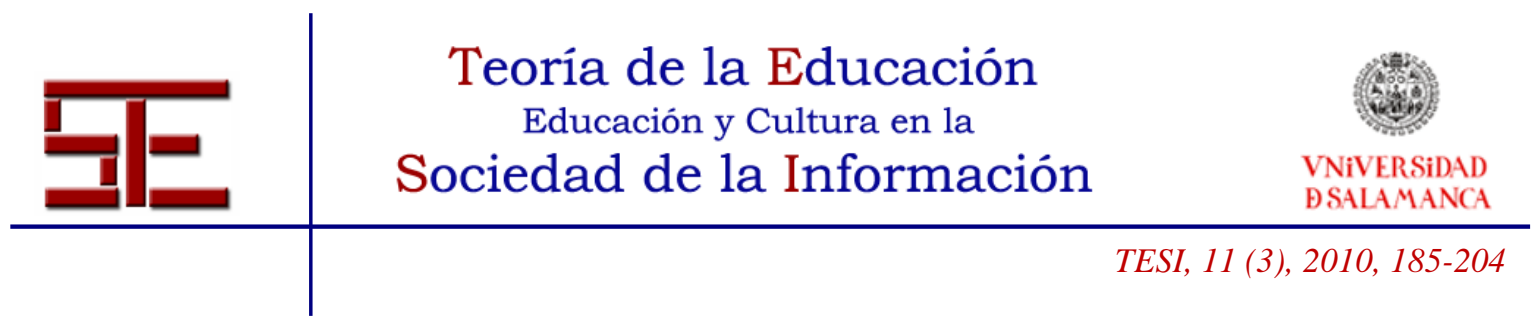

narrative, but this narrative does not exist until the actual performance. It exists during every role-playing game episode, either as a memory or as an actual written transcription by players or gamemaster"5 (Mackay, 1974,50). Véase cómo se tiende a un concepto de realidad mental, creada a partir de los retazos de la narración, ya sea de las interacciones de una partida en mesa, de la desubicación de un escenario o vestuario artificial de un rol en vivo, de un mundo limitado de un videojuego o de la descripción de una partida por escrito.

\section{3.- TAXONOMÍA}

Para esta parte del artículo buscaremos elaborar una serie de clasificaciones funcionales desde una perspectiva pedagógica. Ante cada tipo o modalidad de juego especificaremos posibles puntos de trabajo para la profundización posterior. Ha de entenderse también que, como en toda estratificación de criterios no cuantificables, ciertos juegos pueden quedar a medio camino entre dos grupos o, de hecho, pertenecer a ambos. Véase por ejemplo La última cena (Greenberg, 1999), un manual de rol diseñado para jugarse en mesa, o simultaneando ciertas escenas en vivo.

\section{1.- Clasificación básica. Las cuatro grandes modalidades}

El primer criterio ha sido ya trabajado en el apartado definitorio. Se trata de los condicionantes básicos comunicativos, que generan una serie de necesidades por parte del participante para completar el mundo de ficción que se imagina a través de los estímulos recibidos.

De este modo, se tendría en primer lugar la modalidad en mesa, caracterizada por la interacción verbal entre los distintos participantes. Está limitada a la sala de juego. Para intentar que todos los participantes se hagan a la idea de las descripciones y la situación real de los personajes en las narraciones, suelen encontrarse recomendaciones en los manuales de mapas, ilustraciones, música de ambientación y miniaturas. Como narración fundamentalmente oral, fomenta el desarrollo de aptitudes relacionadas con la interacción social cercana, sobre todo en contraste con el rol en vivo que puede llegar a ser extenuante para alguien con problemas de adaptación. El control se ha de efectuar en el arbitraje y en la selección de contenidos, que se han de adecuar a los jugadores en concreto. Es de todas las modalidades la que más fácil supervisión puede llevar a un formador, pero por contra le hace trabajar con grupos reducidos. Uno de los problemas

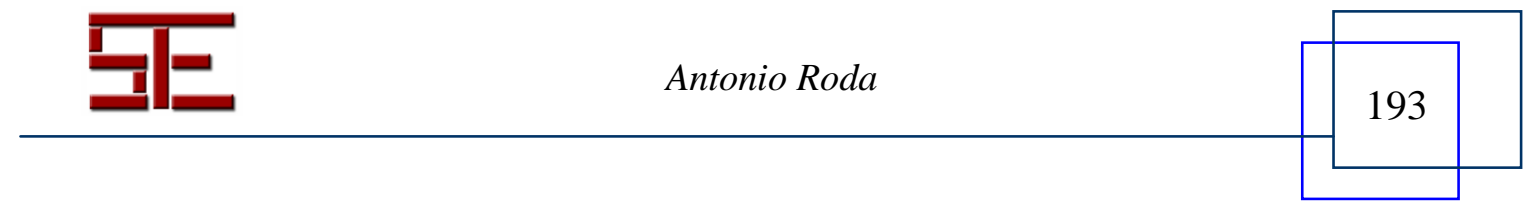




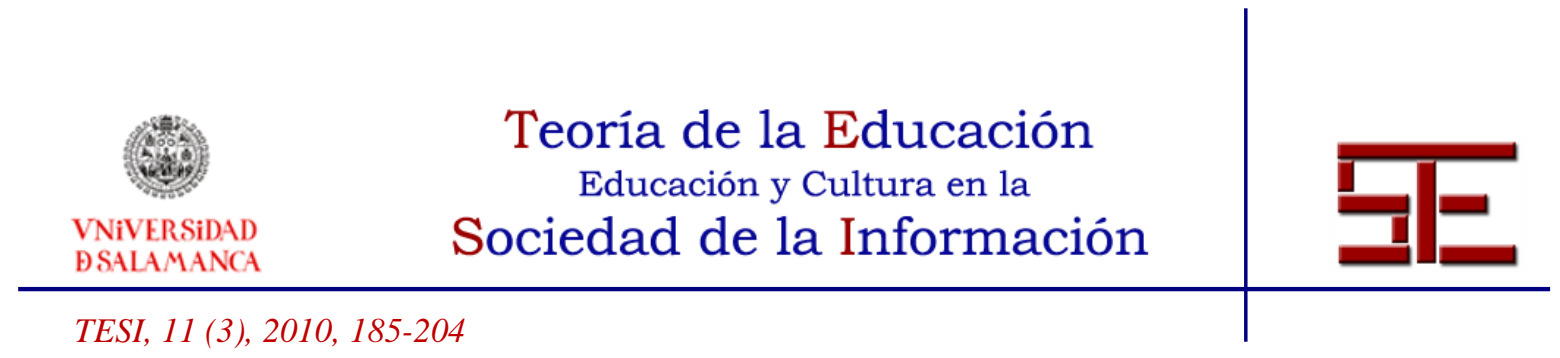

principales es la posibilidad del sedentarismo, puesto que la realización del juego se tiende a hacer con los miembros sentados. Además, debido a la duración de las sesiones, se suele consumir comida basura ${ }^{6}$.

En cuanto a la modalidad en vivo, se define por la utilización del cuerpo y sus recursos expresivos, así como la posibilidad de desplazamiento. La limitación física puede superar en este caso la sala de juego, llegando incluso a enormes extensiones. La posibilidad de adaptación pedagógica de esta modalidad resulta interesante incluso para edades tempranas para lo cual puede considerarse el artículo "El juego de rol utilizado como instrumento pedagógico" (Chico, 1999). En lo positivo, se fomenta el ejercicio físico. Además, el proceso de inmersión en el personaje puede llegar a cotas mayores, jugando con los distintos elementos de la dramaturgia como la preparación del decorado, el vestuario, interacción física entre participantes, etc. Es en este último caso donde hay que prestar una mayor atención al diseñar el juego, puesto que al poder permitirse (o de ser necesario prohibirse) la interacción física entre participantes puede dar lugar a conflictos violentos o accidentes no deseados.

El videojuego de rol viene condicionado por la interfaz. Necesita de soporte informático para jugarse, ya sea a nivel individual o en multijugador. De todas las formas, es la más propensa a generar sedentarismo, aunque las nuevas tecnologías como la Nintendo Wii están acercando poco a poco el videojuego de rol a una auténtica realidad virtual, que permite nutrirse más del rol en vivo que el rol en mesa. Muchos de estos videojuegos sirven de simulacro para situaciones cotidianas. El problema para el formador es que, salvo contadas ocasiones, no puede controlar la generación de contenidos, de forma que se ha de hacer una supervisión por separado de cada juego. Además, aquellos que permiten generar contenidos, como puedan ser los servidores multijugador, requieren de nociones básicas de programación. Es precisamente el ejercicio de la informática en cuanto se necesita profundizar en este mercado uno de los principales pros pedagógicos de esta modalidad.

El juego de rol por escrito viene condicionado por el lenguaje. Frente a las posibilidades orales de los dos primeros, éste usa el lenguaje escrito. Al ser de todas las modalidades la que tiene una retroalimentación más lenta, obliga tanto a los árbitros como a los jugadores una emisión de mensajes en las que se enfatizan los detalles de las descripciones, lo que a su vez sirve de estímulo para las aspiraciones narrativas escritas. En muchos aspectos, el rol por escrito no se diferencia de la co-escritura. El sistema mecánico de juego se deja normalmente en segundo término para no ralentizar el

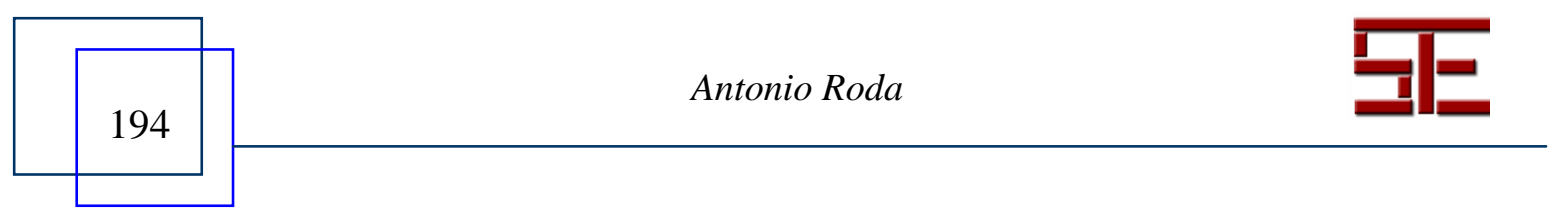




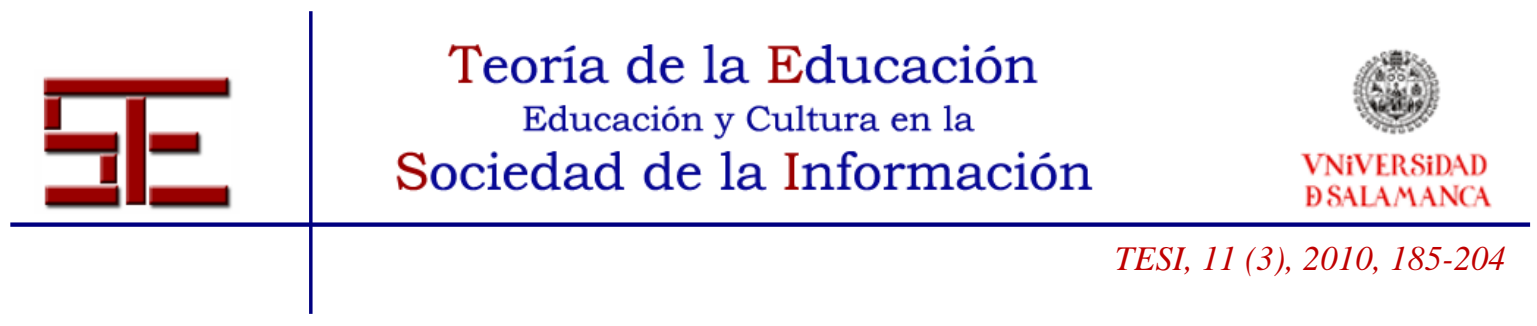

proceso, y en muchos aspectos, sobre todo por carta, es más una cuestión de fe, puesto que es el árbitro quien dice qué ha resultado.

\section{2.- Clasificación de los manuales}

Los manuales de rol son una fuente de información y de formación válida. Independientemente de cualquier otro criterio interno, compensa saber si el idioma original del manual es el mismo que el de consulta, puesto que ante los problemas de traducción los aficionados buscan la referencia original ${ }^{7}$, fomentándose así el aprendizaje de nuevos idiomas, al menos de la lectura.

Más que los tipos de manuales, se va a clasificar la información que puede aparecer en cada uno de ellos. De este modo, un manual estará compuesto de una o más partes.

En primer lugar está el reglamento. Éste explica el sistema de juego, la dinámica que hay entre los distintos participantes y los sistemas de resolución de conflictos. A nivel narrativo, generan los límites de los relatos, en cuanto a que con determinados sistemas de juego ciertos tipos de historia serán inviables. Las aptitudes desarrolladas en esta parte son las que tienen que ver con el pensamiento abstracto y, normalmente, con el cálculo matemático. El contra, que suele resultar una lectura tediosa, que ha de ser amenizada o generará el desinterés. Se tiende a su vez a subdividir entre generación de personajes, arbitraje y diseño de escenarios, en función de para quién esté destinado el manual. Cuando éstos no incluyen una ambientación predefinida ayudan a desarrollar las capacitaciones de investigación, así como a consumir productos narrativos en los distintos formatos para que generen el marco necesario para diseñar las propias historias.

Continúan los manuales de ambientación. Éstos explican en qué consiste el mundo de ficción, ya sea a través de descripciones o de narraciones. Para amenizarlos, varios libros articulan parte como si fueran cartas escritas por habitantes de este mundo de ficción, lo que suele conducir a generar un ambiente propiciatorio a la escritura de las vivencias del personaje. A su vez, generan un marco de trabajo a partir del cual se estimula la imaginación para pensar posibles historias de juego para los diseñadores de partidas.

La representación cuantificada implica la traslación de personajes, lugares y eventos al mundo de juego. Pueden ser tanto de personajes genéricos usados como plantillas para

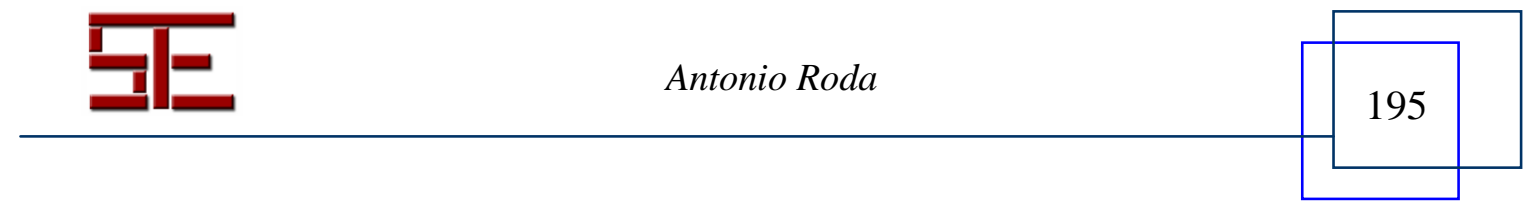




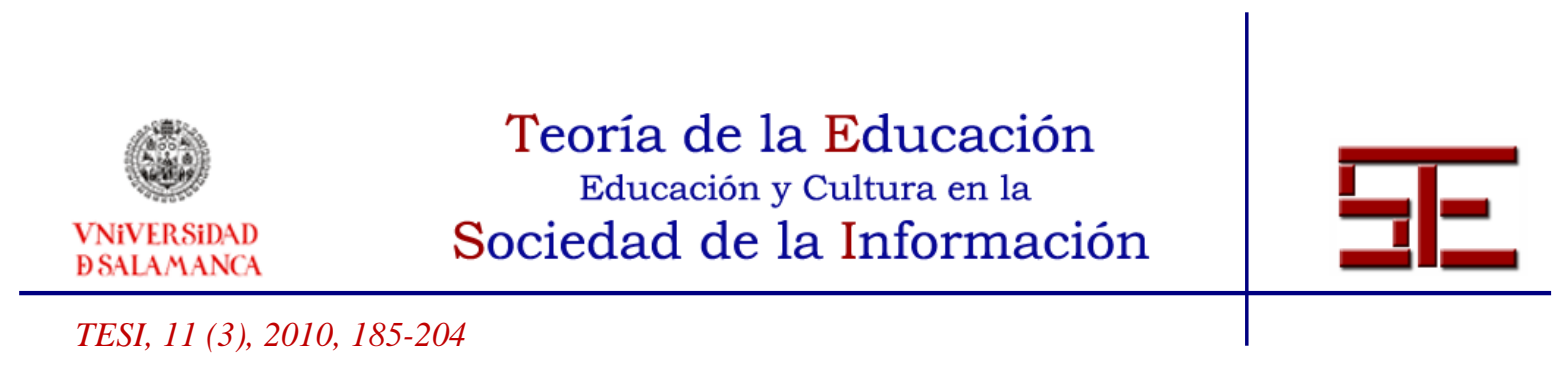

varios encuentros como otros muy concretos con nombre. Esta diferenciación, remarcable desde el aspecto narrativo, puede conllevar a la trivialización de la identidad individual llevando al uso de la violencia dentro del mundo de juego como algo usual ${ }^{8}$.

Siguen las historias jugables, que suelen recibir el apelativo de aventuras. Mantienen una doble finalidad: permiten a los árbitros preparar partidas sin consumir un tiempo excesivo y ayudan a comprender qué posibilidades de juego hay para un sistema o mundo en concreto. Es precisamente en este punto donde más a favor y en contra se puede hablar de la aplicación pedagógica de los juegos de rol. Muchas de estas aventuras consisten en los antes mencionados dungeons, en los cuales los personajes de los jugadores se abren paso usando la violencia, astucia y deducción. Por otro lado, es en el diseño de estas historias donde se puede hacer hincapié a la hora de personalizarse para el tratamiento propicio de los contenidos. De esta manera, se pueden incluir transversalmente elementos como la educación en valores, empatía hacia colectivos desfavorecidos o soluciones no violentas a los conflictos. Este tipo de manuales puede, a su vez, ser de una historia autoconclusiva, de un grupo de historias entrelazadas o ser el punto de partida de una saga de aventuras entrelazadas entre sí.

\section{3.- Clasificación de las ambientaciones}

El mundo de juego puede también condicionar las aptitudes desarrolladas por el juego de rol en concreto. La premisa básica de separación sería según la relación mantenida con el mundo real, la cual puede ser tendiendo a la totalidad, alteraciones sobre un patrón real, adaptando obras de ficción o inventando el mundo de juego. El otro grupo de ambientación sería la ubicación cronológica del mundo de juego en relación a la cronología histórica real, pudiendo encontrarse desde la prehistoria hasta mundos ultrafuturistas pasando por alternativas a nuestro presente. Clasificaremos según la primera premisa y desglosaremos las posibilidades de las segundas en cada grupo.

\subsection{1.- El mundo real}

Aunque se trate de una adaptación literaria o cinematográfica, este tipo de ambientaciones trabajan a partir de la investigación de la realidad, y se ubican en el pasado o el presente de nuestro mundo sin hacer alteraciones en los mismos. Por motivos obvios, no hay juegos de rol futuristas de este tipo.

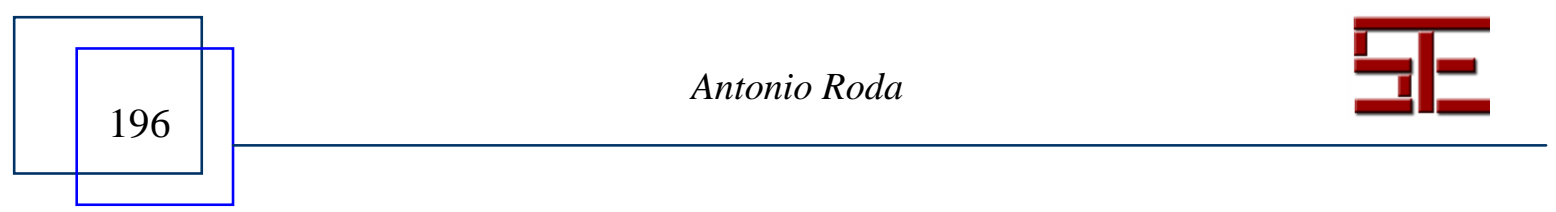




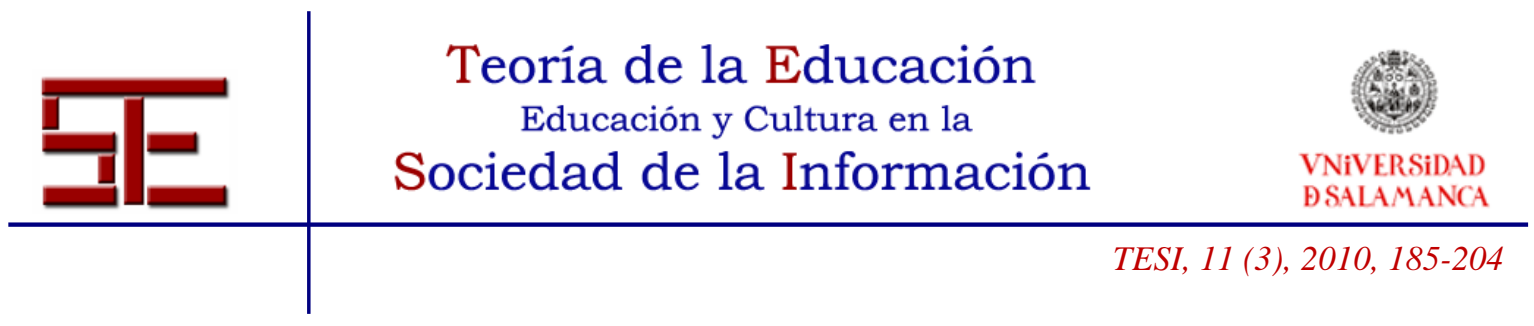

Uno de los principales valores de este tipo de juegos es que ayudan a conocer la historia y el mundo en el que los jugadores viven. Fomentan la investigación fuera del juego sobre cultura, avances científicos, historia, etc. El principal contra es el genérico de cualquier investigación, y es que ésta se haya hecho sin el suficiente rigor dando por hecho elementos cuestionables. Esto puede ocurrir sobre todo debido a que a los diseñadores de los juegos de rol no se les exige una formación determinada, y dependiendo del perfil de edad y educación del lector puede dar por hecho que lo que se le dice es cierto. Suele encontrarse bibliografía dentro de los propios manuales de ambientación, tanto para el cotejamiento por parte de los árbitros como para la ampliación de la información.

La aplicación directa narrativa de estos juegos se da en los intersticios indocumentados. Así, puede plantearse un módulo a partir de personajes del pueblo llano cuyas acciones no hayan pasado a la historia, grupos que operen en la clandestinidad o, incluso, recrear eventos buscando la fidelidad a lo ocurrido.

A nivel pedagógico el problema parte de que esta fidelidad a la realidad puede conducir en un excesivo esfuerzo para los participantes. Si deja de percibirse como juego y pasa a percibirse como trabajo, existe la posibilidad del abandono, y que por tanto pierda la efectividad. En caso de que el rol del árbitro caiga en manos de un formador, puede quitar gran parte de este trabajo a los demás participantes, aumentando por contra su efectividad pedagógica.

\subsection{2.- Mundo real alterado.}

Este tipo de ambientaciones parte de la premisa de que en el mundo de ficción han ocurrido ciertos cambios con respecto a la normalidad de nuestro mundo. Éstos pueden ser de menor o mayor cuantía, desde alteraciones en la historia hasta que lo fantástico sea posible y viva oculto o en público.

En cuanto a la temporalidad, se exploran los cambios producidos desde el pasado. Dependiendo de cuánto tiempo haya permanecido la línea temporal diferenciada de la nuestra real, más trabajo se tiene que hacer desde el diseño para que el mundo de juego mantenga coherencia en el presente de las partidas de rol. Téngase en cuenta que no se está hablando del presente real, si por ejemplo la partida se ubica en la Edad Media y el cambio se ha producido el día antes de la partida se cuenta como que se ha producido sólo un día de alteración. Lo que se busca en estos casos no es en sí el realismo, sino la

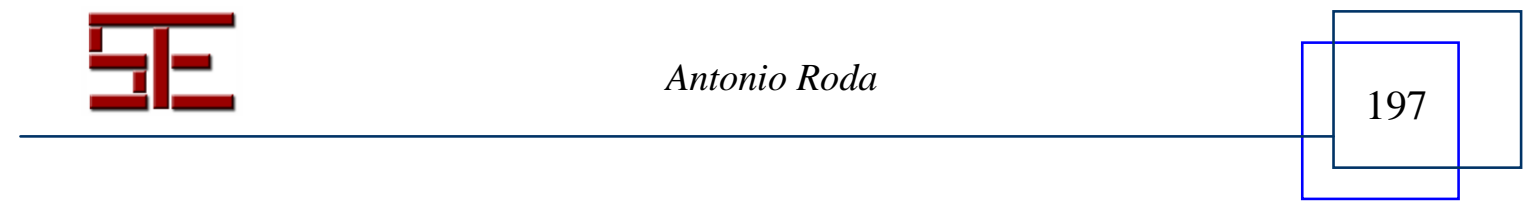




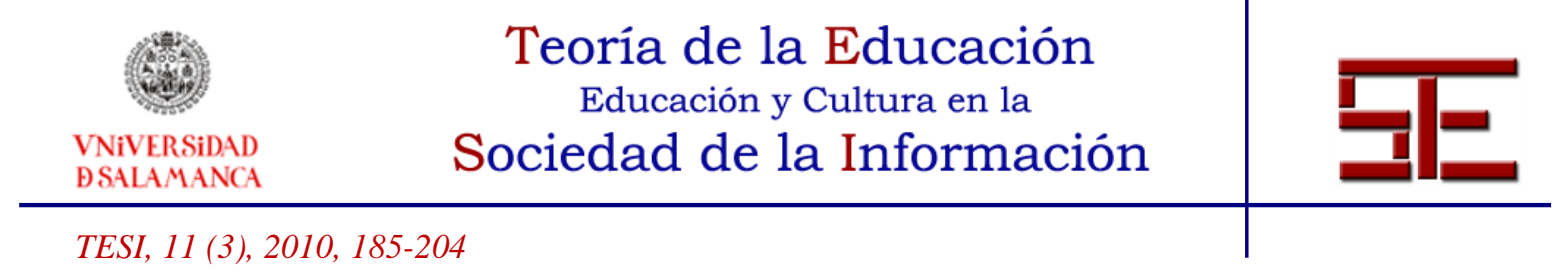

verosimilitud, que puede alterar el devenir real de los acontecimientos en pro de la "poética de la ficción" (Doležel, 1998: 38), en contraste con la veracidad del caso anterior.

En este caso se permite explorar mundos futuristas a partir del nuestro. Esto permite trabajar con conceptos más allá de los límites de la cronología real, trayendo propuestas a la mesa de juego como mundos devastados por guerras, por el calentamiento global o por la globalización extrema.

El estudio exhaustivo recae sobre todo en árbitros y diseñadores, quienes tienen que ver y asesorarse con cuidado a partir de los cambios posibles que se hacen en el mundo. Por tanto, el estudio de los distintos parámetros de validez pedagógica habrá que hacerlo de cada manual por separado. Estos valores son prácticamente los mismos que en el apartado anterior, sólo que las variaciones permiten una cierta flexibilidad la cual relaja parcialmente la labor de documentación generando así la posibilidad de confundir qué elementos son del mundo real y cuáles aportaciones de la ficción.

Varios de estos juegos, como ocurre con el ya mencionado La llamada de Cthulhu (Petersen, 1994), son adaptaciones de obras de ficción. A diferencia de las tratadas en el apartado siguiente éstas se basan en el mundo real estableciendo cambios en el mismo en menor o mayor cuantía. Estos juegos conllevan a la exploración de estas obras tanto para los jugadores como para los árbitros, lo que a su vez conduce a un fomento de la cultura ya sea a través de la lectura o del audiovisual.

\subsection{3.- Mundos de ficción inventados en obras previas}

A la hora de contemplar estos mundos hay que tener en cuenta que tienen una cronología propia específica, la cual puede estar más o menos desarrollada. Los árbitros perciben ésta con una mayor laxitud, pudiendo hacerse un juego más o menos purista en cuanto al respeto de la misma. Sea como fuere, la necesidad de documentación es considerablemente menor que en los juegos desarrollados en mundos equiparables al real.

La equiparación cronológica ha de hacerse en comparación a la mantenida por el mundo real. Puede, al tratarse de la ficción, que ciertos elementos estén más avanzados y otros más atrasados, teniendo que ubicarse estructuralmente en un punto y especificándose la diferenciación.

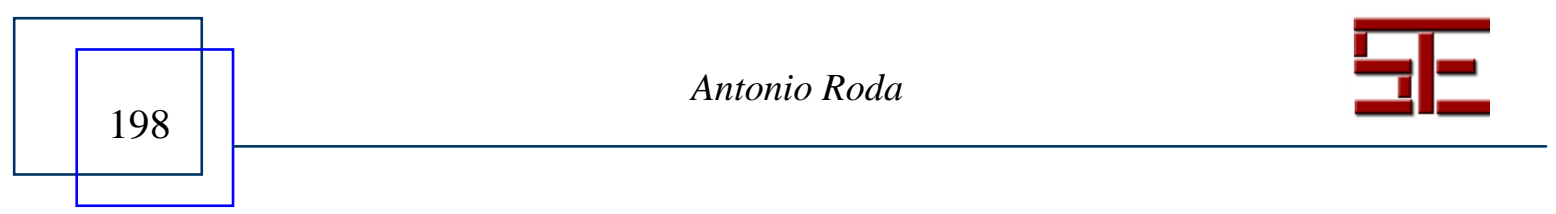




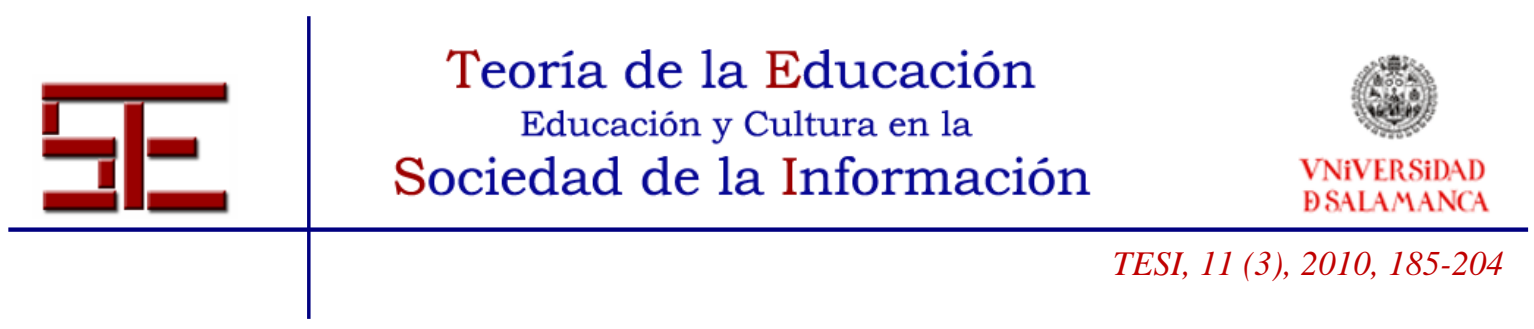

La principal cualidad, por tanto, coincide con lo mencionado al final del punto anterior: el consumo de la obra de origen y el hábito que puede llegar a generarse de la lectura o visionado de otras obras similares.

Por otro lado, hay que considerar que la cronología, costumbres y tecnologías del mundo de ficción son incompletas respecto a la real, por lo que fomenta la imaginación de jugadores, árbitros y diseñadores tener que rellenar todos los huecos de creación dejados por hacer en las obras originales.

\subsection{4.- Mundos de ficción creados para el juego}

En último lugar están aquellos cuyos mundos de ficción han sido desarrollados para el mismo juego. Éstos suelen proponer una cronología oficial hasta una fecha dada, la cual se considera la ubicación perfecta para el desarrollo de cada partida. Por tanto, se puede afectar en las narraciones el devenir de los acontecimientos, puesto que cada grupo de juego ofrece su posibilidad.

La principal ventaja de este tipo está en el fomento de la creatividad y la imaginación, como evolución en continuo de lo hablado para el grupo anterior. Suelen a su vez ser los manuales que incluyen una mayor cantidad de ilustraciones, y para los cuales se fomentan las capacidades de descripción cuando no se tienen las referencias visuales.

Por contra, son los más dados a la trivialización de cuestiones referidas a la violencia, ilegalidad y derechos humanos. Esto es más un elemento dado de la elaboración de los manuales en pro del sistema de juego táctico, herencia de los juegos de guerra, que de los mundos de ficción en sí. Téngase en cuenta que el arco que se abre aquí es infinito, y por tanto da pie a todas las posibilidades, tanto las que desarrollen las aptitudes necesarias como las que hagan lo propio con las opuestas.

Por supuesto, las capacidades icónicas no resultan desarrolladas en los videojuegos con interfaz gráfico, puesto que se percibe como gráficos elaborados por los creadores. Por contra, en la modalidad en vivo se llega a un término más complejo, teniendo que dar forma física mediante disfraces y decorados a los elementos de ficción.

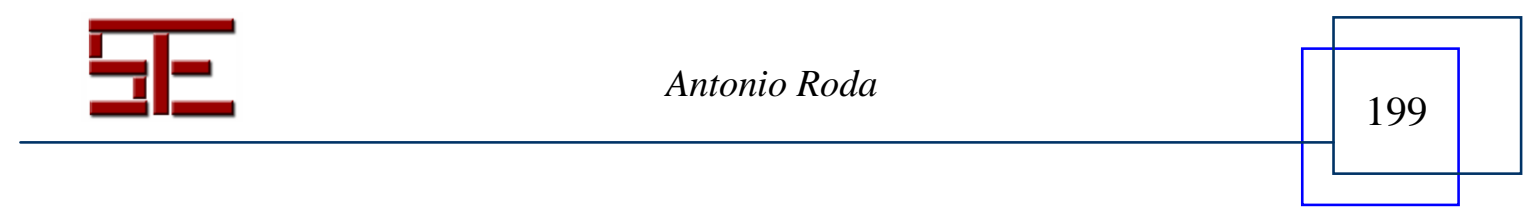




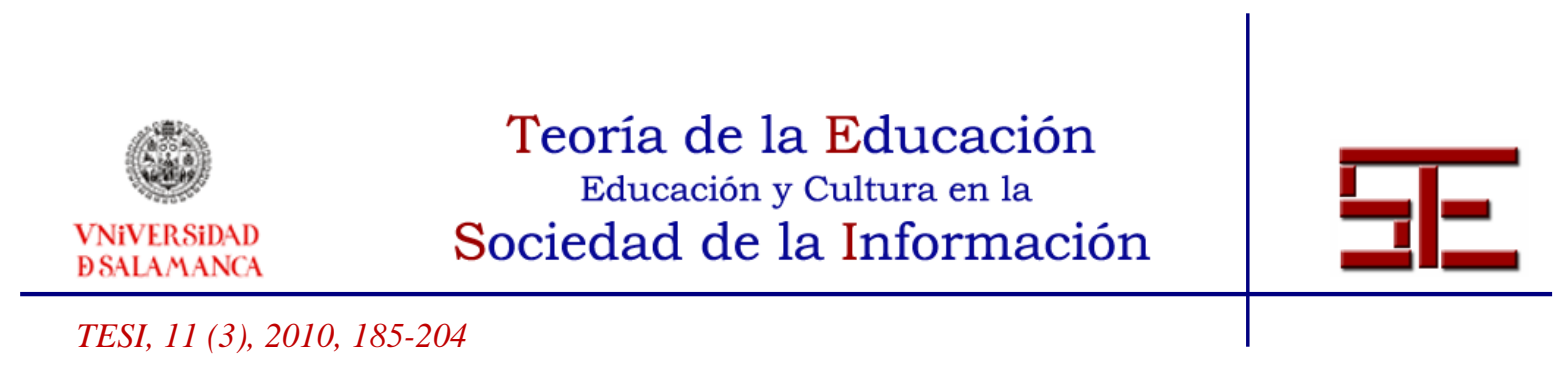

\section{4.- Clasificación por género}

Este último elemento de clasificación depende de los géneros narrativos predominantes en cada tipo de juego. Para ello pueden tomarse como marco teórico los géneros literarios, cinematográficos o, tras un estudio más exhaustivo y detallado, crear un criterio propio. El principal problema que puede atisbarse tras las cuestiones previamente mencionadas es que el género predominante desde el inicio es el de acción. Se deja, por tanto, este apartado por desarrollar en análisis posteriores.

\section{4.- CONCLUSIONES}

El juego de rol se muestra, por tanto, como una herramienta que sobre todo permite desarrollar las capacidades de lectura, interacción social, escritura e imaginación. Dependiendo a su vez de su modalidad, tipos de manual, la clase de mundo de ficción y del género las capacidades para la transmisión de contenidos y aptitudes varían.

En general, la labor que condiciona en su mayoría tanto qué contenidos pueden impartirse a través del juego de rol como qué aptitudes se desarrollarán pertenece tanto al árbitro como al desarrollador de la historia. Un docente ha de implicarse en ambos campos para poder pormenorizar con detalle los distintos elementos necesarios para su desarrollo productivo.

Debido a los condicionantes del juego de rol, es importante desarrollar competencias en el ámbito de la narrativa. La generación de los puntos de interés, dosificación de la tensión dramática, elaboración de personajes interesantes, etc. Todo ha de hacerse en conjunción con los contenidos a enseñar. El campo está abierto al trabajo, cuestionándose qué puede transmitirse a través del juego de rol, y qué no.

Una de las cuestiones que conviene trabajar con detalle es el perfil de edad para cada tipo de contenidos, así como el número de participantes. Una partida de rol en mesa suele requerir un árbitro por cada seis jugadores aproximadamente, y una partida en vivo puede oscilar dependiendo de la complejidad. Precisamente el videojuego de rol es el que más control permite a los administradores, puesto que no necesitan estar sempiternamente encima de los jugadores pudiendo dejar programados acontecimientos.

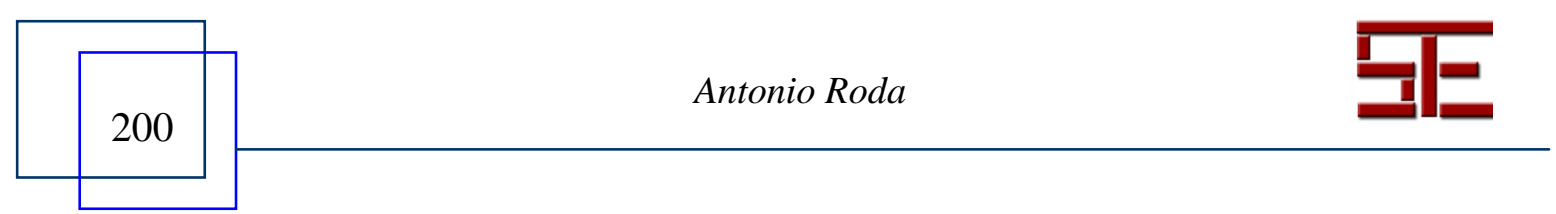




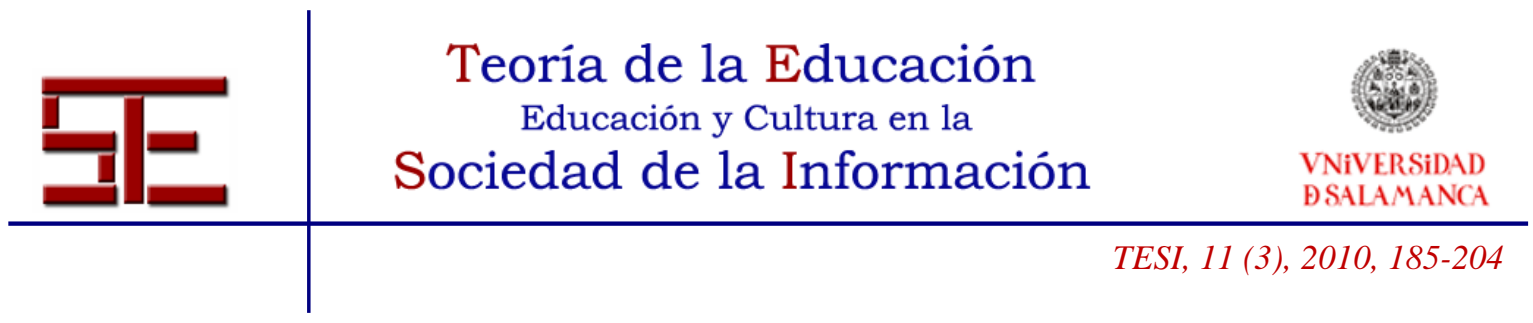

Otra cuestión está en trabajar con el rol como forma de ocio genérica, en cuyo caso habría que fomentar ciertos tipos de juegos frente a otros. Para ello, conviene también hacer un impacto de edades, y unas herramientas de supervisión. Al igual que ocurre con los demás medios narrativos, como el cine o los libros, conviene supervisar qué se transmite en estos juegos. Esta responsabilidad no recae en el caso de la infancia y la juventud en el formador, sino también en la familia, quien puede en una tienda elegir qué manual regalar, no sólo valiéndose para el juicio de la ilustración de la portada. Conviene para ello crear un sistema de reseñas válido desde la perspectiva pedagógica, para que se pueda saber qué se está consumiendo.

\section{5.- BIBLIOGRAFÍA.}

Bridges, J. y Greenberg, A. (1996). Fading suns. EEUU: Holistic Design Inc.

- (1998). Fading suns. Madrid: La Factoría de Ideas.

Castranova, E. (2006). Synthetic Worlds. The business and culture of online games. Chicago: The University of Chicago Press.

Chico, R. (1999). El juego de rol utilizado como instrumento pedagógico. Aula de innovación educativa, 80, 24-25.

Dolezel, L. (1998). Heterocósmica: Ficción y mundos posibles. Madrid: Arco/Libros.

Fatland, E. (2005). Knutepunkt and Nordic Live Role-playing: A crash course. En Bockman, P. y Hutchison, R. (eds.) (2005). Dissecting larp, (pp. 11-20) Oslo: Knudepunkt. Disponible en Internet. Extraído el 13 de mayo de, 2009, de http://knutepunkt.laiv.org/dissectionlarp.pdf. 13 de mayo de 2009.

Fine, G. A. (1983). Shared Fantasy. Chicago: The University of Chicago Press.

Greenberg, D. (1999). La última cena. Madrid: La Factoría de Ideas.

Hughes, J. (1988). Therapy is Fantasy: Roleplaying, Healing and the construction of Symbolic Order. Presentado en Anthropology IV Honours, Medical Anthropology

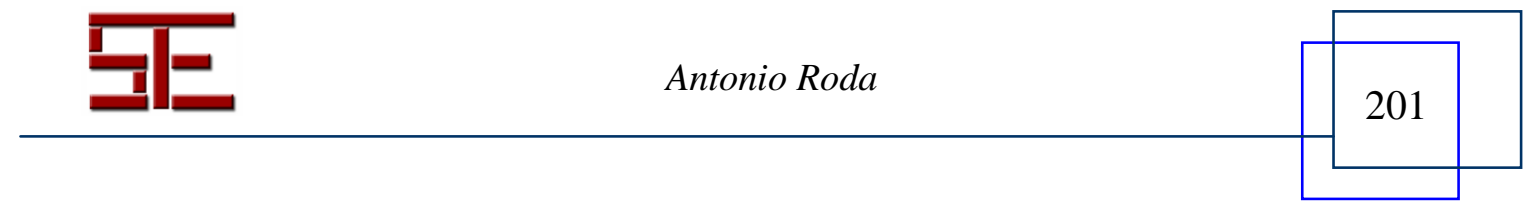




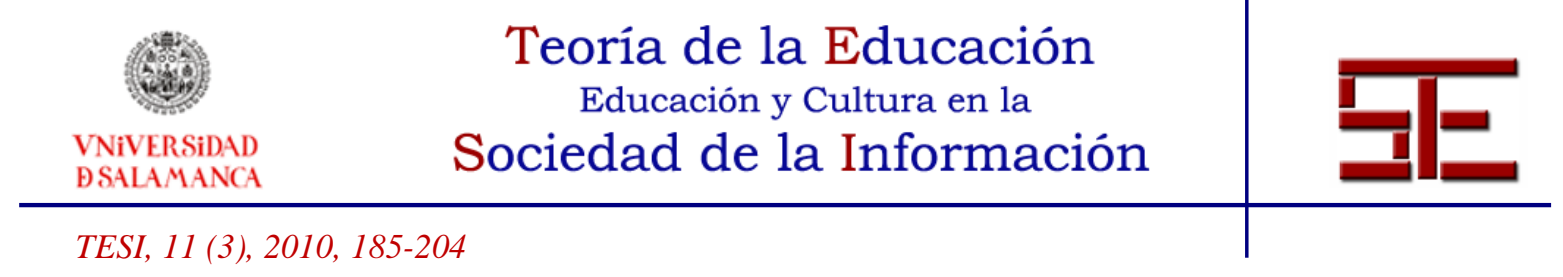

Seminar, Dr. Margo Lyon, Dept. of Prehistory \& Anthropology, 181 Australian National University. Se puede localizar en http://www.rpgstudies.net/hughes/therapy_is_fantasy.html.

Ibáñez, R. (2001). Aquelarre: La tentación. Barcelona: La Caja de Pandora, S.L.

Jackson, S. (1991). Killer. Juego de rol en vivo. Barcelona: Joc Internacional.

Laws, R.D. (2006). Los Esoterroristas. Sevilla: Edge Enteirtainment.

Mackay, D. (2001). The Fantasy Role-Playing Game: A New Performing Art. Jefferson (Carolina del Norte, Estados Unidos de América): McFarland \& Company, Inc.

Mentzer, F. (ed.) (1983). Dungeons \& Dragons: Players Manual. EEUU: TSR Hobbies Inc.

Petersen, S. (1994). La llamada de Cthulhu. Barcelona: Joc Internacional.

Ranera Sánchez, P. (1999). Juegos de rol: experiencia en los mundos de lo imaginario. Tesis inédita. Madrid. Universidad Complutense de Madrid. Facultad de Ciencias Políticas y Sociología. Departamento de Antropología Social.

Rein•Hagen, M., Lemke, I. y Tinney, M. (1999). La Mascarada: El Juego de Rol en Vivo. Madrid: La Factoría de Ideas.

Ryan, M.L. (2004). El ciberespacio, la virtualidad y el texto, en Sánchez-Mesa, D. (Comp.) Literatura y Cibercultura. Madrid: ARCO/LIBROS. 73-115.

Soanes, C. y Stevenson, A. (eds.) (2006). Oxford Dictionary of English. Nueva York: Oxford University Press.

Taylor, T.L. (2006). Play between worlds: exploring online game culture. Cambridge, Massachussets: The MIT Press (Massachusets Institute of Tecnology).

Tynes, J. (2003). Puppetland. Un juego narrativo manejado con hilos en un lúgubre mundo de ensueños/Power Kill. Un metajuego de rol por John Tynes. Sevilla: Edge Entertainment

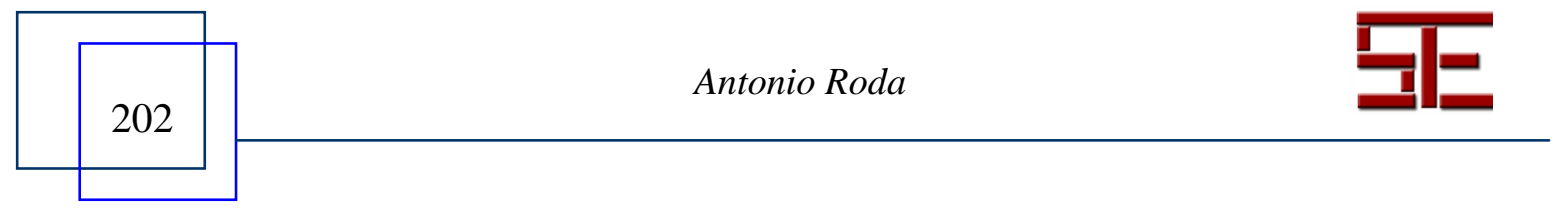




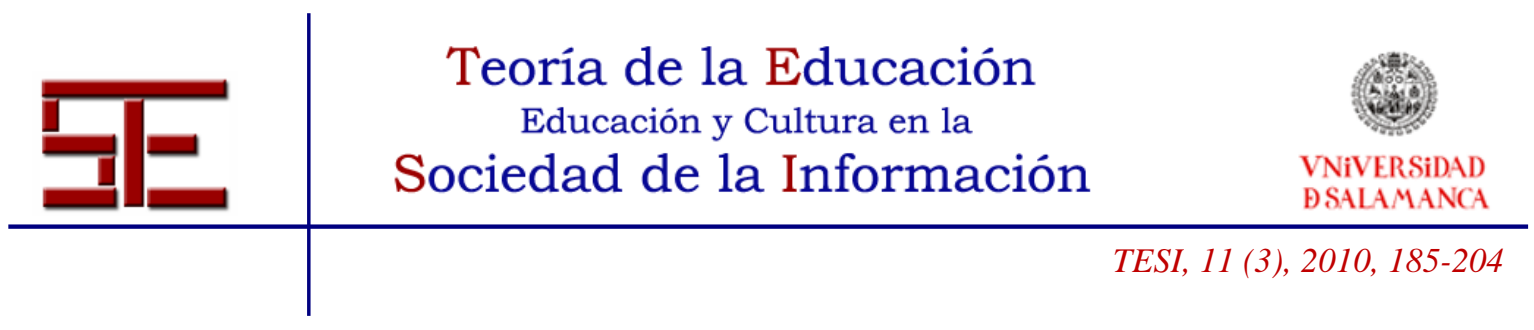

\section{NOTAS}

\section{1.- Traducción personal:}

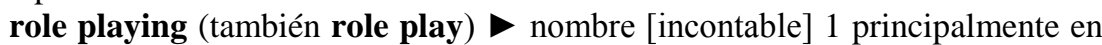
Psicología el acto o interpretación de un rol particular, sea consciente (como técnica en psicoterapia o entrenamiento) o inconscientemente, de acuerdo con las expectativas percibidas por la sociedad como miradas de la conducta de una persona ante un contexto particular.

2 participación en un role-playing game

- DERIVACIONES role-play verbo. role player nombre.

role-playing game nombre un juego en el que los jugadores toman los roles de personajes imaginarios que se dedican a buscar aventuras, típicamente en un entorno de fantasía supervisados por un árbitro.

2.- LARP es un acrónimo de Live Action Role-play. En la traducción de esa expresión cabe el problema de si traducir la palabra play por "jugar", "representar" o "interpretar". Podría ser tanto "juego de rol en vivo" como "representación de rol en vivo" o "interpretación de rol en vivo". La primera, por su unión a los juegos de rol en mesa, ha quedado como expresión genérica y aceptada.

3.- Traducción personal: “(...) un grupo de habitaciones y corredores en los que pueden encontrarse monstruos y tesoros"

4.- Traducción personal: "Esto es un juego de rol. Lo que significa que serás como un actor, imaginando que eres alguien diferente, y fingiendo ser ese personaje. Sin embargo no necesitarás un escenario, ni trajes o libretos. Sólo necesitas imaginar".

5.- Traducción personal: El juego de rol presenta un narración, pero ésta no existe hasta la representación misma. Existe durante cada episodio del juego de rol, o como un recuerdo o como una transcripción real de jugadores o director de juego" (Mackay, 1974,50).

6.- No es necesario recurrir a los estudios sociológicos de Fine o Ranera Sánchez para comprobar esto. No suele ocultarse ni por los propios manuales, llegando a ser elemento de parodia. Tómense como referencia los relatos online de Al Bruno III, conocido como Ab3, los cuales pueden consultarse en http://members.dodo.com.au/ teeshy/jorge/ab3/ab3_intro.htm.

7.- Tómese como ejemplo el juego de rol Fading suns, que debido a un error tipográfico en original, coincidiendo con un salto de página, la palabra "peasant" se dividió en "peas" y "ant" (Bridges y Greenberg, 1996,6 y8) siendo traducido como "hormigas guisante” (Bridges y Greenberg, 1998, 6).

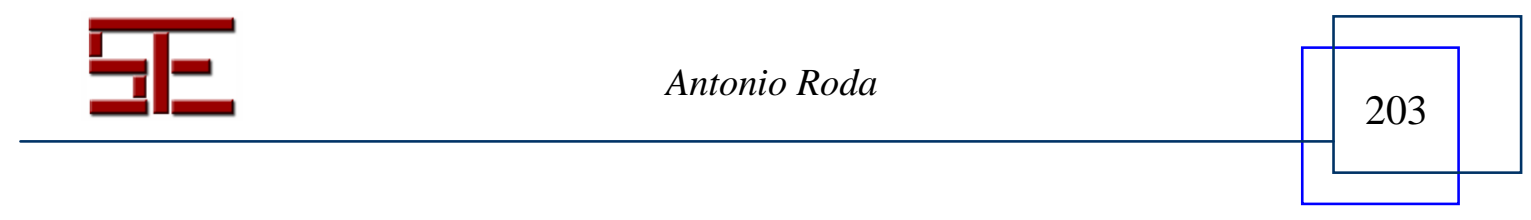




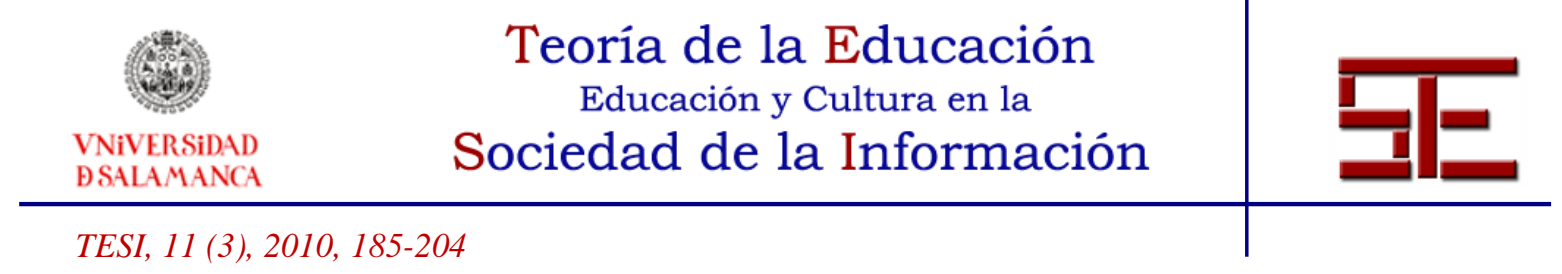

8.- El metajuego de rol Power Kill (Tynes, 2003) establece una reflexión sobre este fenómeno que se produce en muchos de los juegos de rol comerciales. El autor da acceso público a esta obra en la siguiente página web: http://johntynes.com/revland2000/rl_powerkill.html (18 de mayo de 2009).

Para citar el presente artículo puede utilizar la siguiente referencia:

Roda, A. (2010). Juego de rol y educación, hacia una taxonomía general, en Orejudo González, J.P. (Coord.) Perspectiva educativa y cultural de "juego de rol". Revista Teoría de la Educación: Educación y Cultura en la Sociedad de la Información. Vol. 11, $\mathrm{n}^{\circ}$ 3. Universidad de Salamanca, pp. 185-204 [Fecha de consulta: dd/mm/aaaa]. http://campus.usal.es/ revistas_trabajo/index.php/revistatesi/article/view/7458/7474 